\title{
The Culture of Information Systems in Knowledge-Creating Contexts: The Role of User-Centred Design
}

\author{
Natalie Pang and Don Schauder \\ Faculty of Information Technology, \\ Monash University, Australia \\ natalie.pang@infotech.moash.edu.au \\ don.schauder@infotech.monash.edu.au
}

\section{Abstract}

Examining communities in all their meanings, the paper locates UserCentred Design (UCD) in the amplified scope of approaches to Information Systems Design (ISD). Culture in communities is explained in structurational terms, in which human action and social structure (including ICT) interact to produce and reproduce the social patterning that both supports and constrains action. The widening of the spectrum of ISD approaches has paralleled the supplementing or superseding of Fordist methods of production by knowledge-based production. The transition to an ICT world characterised by personal computing and the Internet is identified as key threshold (referred to as the PC/I or Personal Computing/Internet threshold) necessitating the development of user-centric concepts alongside more established technocentric approaches. Noting the diversity of understandings in UCD, the paper proposes an approach to consider the wider relationship of tasks and community cultures. The aim is to explore the feasibility of a participative and reflexive design, resulting in design practices that are an emergent property of community culture. The research is based on case studies in the cultural institutions' sector, and one of the cases is outlined.

\footnotetext{
Material published as part of this publication, either on-line or in print, is copyrighted by the Informing Science Institute. Permission to make digital or paper copy of part or all of these works for personal or classroom use is granted without fee provided that the copies are not made or distributed for profit or commercial advantage AND that copies 1) bear this notice in full and 2) give the full citation on the first page. It is permissible to abstract these works so long as credit is given. To copy in all other cases or to republish or to post on a server or to redistribute to lists requires specific permission and payment of a fee. Contact Publisher@InformingScience.org to request redistribution permission.
} 
Keywords: user-centred design, structuration theory, community informatics, knowledge creation, reflexive design, participatory design, cultural institutions

\section{Introduction}

This paper arises from a project whose aim is to explore whether and how cultural institutions, particularly museums and libraries, can engage with their users in a continuous, co-creative design process that addresses both opportunities and problems in the age of digitisation. The project will be based on a series of case studies, one of which will be briefly described. However the purpose of this paper is to explore some of the general system design issues seen to be relevant to the specific project at hand, and perhaps to other similar projects.

Community' is used in this paper in its widest sense, including communities of practice, communities of interest, local and virtual communities (Wellman \& Haythornthwaite, 2000; Wenger \& Snyder, 2000). It covers not only corporate-based communities, but also the vast variety of communities that make up civil society as defined by the World Summit on the Information Society (Schauder, Johanson, \& Taylor, 2006). The essential property of communities, as the term is used in this paper, is that they are sites of discourse where meaning is recursively made and re-made. This paper aims to explore design principles through a focus on communities - a community-based approach where the interpretive dynamics of communities are considered.

The term 'User-Centred Design (UCD)' is much used, but still there appears to be only a basic consensus as to its meanings and implications: the consensus that 'user' needs should inform processes of information systems design. This paper argues for a concept of UCD that draws its procedures, and its explanatory and prescriptive power, from the interpretive study of communities in which people live and work. In this it owes much to the task-based approach to Knowledge Management developed by Burstein and Linger (2003), concepts of Community Informatics as pioneered by Gurstein (2000) and, at a fundamental level, structuration theory as developed by Giddens and others (Giddens, 1984; Orlikowski, 1992; Orlikowski \& Robey, 1991), and elaborated in the Information Continuum Model developed by Upward, Schauder and others (Schauder, Johanson, \& Stillman, 2005). 
The cumulative effect of people's living and working within social frameworks (through a dynamic that Giddens calls structuration) is the production and re-production of culture. The cultural context is generated and re-generated through the interplay of action and structure the 'duality of structure'). Social structure both supports and constrains the endeavours of individuals, communities and, societies. The implications for design arising out of structuration theory is an important one and will be elaborated in a later section.

An interpretive approach to UCD implies a fine-grained study of the relationships and interactions among people in their creation and recreation of community culture manifested in the knowledge and practice of community members. For the purpose of studying this, case studies of cultural institutions are undertaken through procedures of grounded, reflexive analysis.

Cultural institutions are defined in this study as organizations whose charter is to promote and support education, arts, and sciences through creating, preserving, sharing and transmitting knowledge - a definition consistent with UNESCO's Virtual Exhibition on the knowledge society (UNESCO, 2003). For the purpose of this research, case studies from museums and libraries in Australia and Singapore are considered.

Within the broad aim of the project as stated in the first paragraph of this paper, the study has two goals:

a) To assess how far collaboration between cultural institutions and communities can be characterised and explained as ongoing processes of adaptive UCD. In this context cultural institutions are considered as systems for the creation, preservation, sharing and transmission of public knowledge in communities.

b) To apply insights from this assessment to the future development of museums and libraries as components of 'the knowledge commons'. The commons is a concept with deep historical roots that has been brought into current prominence by the capacity of digital technologies to facilitate endeavours in the public co-creation and use of knowledge resources.

The following sections of this paper seek to elaborate some of these key ideas and objectives, with particular reference to the question of whether and how UCD is applicable to the continuous, adaptive codesign of 'knowledge commons' systems such as cultural institutions. 


\section{User-Centred Design}

Poor relationships between the 'users' and computer scientists often arose out of techno-centric approaches to design; commonly referred to as the IT/User gap (Mann, 2002). Towards this several contributing factors have been cited: a lack of understanding about user needs and the broader implications of these needs; a lack of understanding about IT by users; and an absence of empowerment because of these misunderstandings (Mann, 2002; Stowell, 1991).

The fundamental concepts of UCD originate from critical research and pioneering management projects as far back as the 1970s. Although the term, user-centred design, was first formally expounded by Norman (1986), the underlying principles of UCD reflected broad based concerns in social science and management about the limitations of prescriptive design. Researchers and managers embarked on a critique of the 'scientific management tradition' founded by J.P. Taylor and turned to Scandinavia and Japan for examples of how the engagement of workers in the design of production processes could improve productivity and competitiveness. Scandinavian efforts to conceptualise 'worker-centred design', pioneered by Volvo, were based on essentially the same principles as UCD. So were a range of endeavours associated with the action research movement. In the words of Whyte, writing in 1986:

It is striking that researchers are reaching the same general conclusions in fields so divergent as industry in highly industrialized countries and agriculture in developing nations. In conventional organizations in both fields we find the same tendency of those in power to grossly underestimate the intellectual contribution that could be made by the powerless if the social systems were restructured so as to facilitate and utilize that contribution. (p. 561)

The study, of which this paper is a preliminary stage, attempts to extend the notion of UCD into the area of participative, adaptive design on the part of communities, drawing of key ideas from structuration theory.

While not attempting to define or even re-define UCD, the paper now discusses the very message inherent in the term. The term UCD signals that this approach locates itself on a different part of the spectrum from other approaches to information systems design (ISD), although 
it need not be completely distinct from them. The basis of this differentiation is the claim that, more than other approaches, it focuses on human needs ahead of perceived technological imperatives as the prime consideration in ISD.

What is the value proposition underlying such an approach? Is it just a sentimental fad, pandering to a view that corporate life - and indeed the whole demanding business of everyday living - can be something other than goal directed, tough and earnest? As can be observed through everyday experience, and as attested in the literature (Walsham, 2001), information and communication technologies (ICT) has become essential and almost ubiquitous in contemporary society. From initial applications in the military and 'big science' sectors, the utility of ICT has been recognised and applied in all manner of organisations, in the business, government and civil society sectors. The ascendancy of ICT owes much to ISD approaches that are driven more by the potentialities of technologies to perform certain tasks than by an understanding of human needs, and the social ramifications of technological interventions (Culnan, 1984; Faulkner, 1998). At this point, it is important to note that there is an ever increasing engagement in developing social theories of ICT (Katsikides, 1998; Pinch \& Bijker, 1989). Sceptics of UCD could argue that to date the success of ICT has owed little to notions such as UCD. With such a proven track-record of success by other ISD approaches, why does the ICT world need UCD?

An approach such as UCD is more consonant with humanity's best aspirations as expressed in the UN Universal Declaration of Human Rights, especially Articles 19 and Article 27 which assert the right of every individual to freedom of communication in any medium. That vision has been supplemented more recently by Article III.20 of the UN's Millennium Declaration which states 'that the benefits of new technologies, especially information and communication technologies ... [should be] available to all'. In these declarations of rights of which the prime concern is to widen the scope of action for the individual: ICT is foremost a means of making humans more autonomous and empowered, not just human components of a production system.

Other 'user-centric' charters relevant to ICT include those of the International Association of Media and Communications Researchers (IAMCR), the Budapest Open Access Initiative, the Berlin Declaration, the Creative Commons, and the Open Courseware Initiative (Schauder et al, 2006). 
However the argument for an adaptive, community oriented appoach to UCD in this paper only partially rests on such visions of individual empowerment in the age of digitisation. Current society is characterised by the almost ubiquitous availability of digital networks that can facilitate human communication, learning and other action. For the purpose of this paper we refer to such a societal state as the knowledge society. The paper also argues from the premise that current technological condition of society is in fact making the more 'techno-centric' approaches to ISD relatively less potent in a range of contexts than 'user-centric' approaches.

Kaufer and Carley (1993, p. 99) define the technological condition of a society as: ' $\ldots$ a set of available technologies and their distribution across individuals in the society'. Ubiquitous digitisation is a fundamental change in the technological condition of society globally, affecting everyone whether directly or indirectly. In the language of complex systems science (Price, 2004) the processes of emergence accompanying such fundamental and widespread change can be described as a threshold change. In this paper we have coined the term PC/I (Personal Computing/Internet) threshold to characterise the change. The revised approach to UCD which this paper seeks to explore in a preliminary way is seen as just one way, among many possible processes of adaptation and adjustment, to address both opportunities and problems arising from the post PC/I technological condition of society.

\section{Design of Informing Systems: A Historical Perspective}

It could not have been anticipated, but is clear in hindsight, that ultimately techno-centric approaches to ISD would need to be supplemented by some form of UCD. The impulse towards this development originated within the techno-political development trajectory of ICT, especially since the late 1940s. The paper begins this section with lessons from history; but the purpose of this is to help provide background and rationale for the UCD approach being proposed.

\section{Shift from Fordism to the knowledge society: ISD consequences}

The professional discipline of IS was initially strongly influenced by the age of mass production - beginning with the Industrial Revolution of the 18th century, and refined by Taylorism and Fordism in the early 
20th century. The technologies of industrialised warfare brought techno-centric views of information systems into high focus by the end of WWII, and this trend was reinforced by the needs of the militaryindustrial complexes that dominated the Cold War era.

Under the threat of mutual nuclear annihilation, the possibility of powerful, independently-operating microcomputing technologies was conceived. This possibility resulted in the explosion of personal computing in the late 20th century. In tandem, the potentially decentralised, selforganising technology of the Internet was developed. As explained, in this paper the transition from large centralised computing with noninteroperable networking arrangements to autonomous decentralised computing with a globally interoperative Internet is referred to as the 'PC/I (Personal Computing/Internet) threshold'.

Out of these technological developments grew the possibility of a wide range of individuals and communities reclaiming their power over information technologies - a power which had waxed and waned through the millennia as orality, writing, and graphic and print communication, contended and co-evolved as information technologies - certainly the transition to print technology was a threshold as profound as the PC/I.

The potentials for a more holistic information environment created after passing through the PC/I threshold unleashed the energy behind the 'knowledge society' declarations and charters cited above, and behind such agendas as the World Summit on the Information Society. As observed, the ideals of open communication basic to the knowledge society were clear in the pre-digital Universal Declaration of Human Rights (and were evident as far back as the framing of the Constitution of the United States of America). However it was the PC/I threshold transition that prompted the Millennium Declaration and the movement in which the two parts of the UN/ITU World Summit on the Information Society in Geneva 2003 and Tunis 2005 were focal events.

The same energy that, through the Millennium Declaration and WSIS, updated concepts of open communication for the digital age is, we argue, a key part of the UCD story.

The techno-centric approach to production, including its IS dimensions, stems in part from the circumstances of a much leaner information environment, where only the experts - the designers - could have continuous and up-to-date access to essential information sources. Since the majority of stakeholders affected by a design regime (the 
workers, the users) could not access a substantial part of the knowledge base, they must take the design on trust or at least as a given. The resulting technological condition of society was that human beings must adapt to technology, rather than vice versa. Success was achieved when tasks are broken down into the simplest possible components - 'bite sized' -, and organised such that minimal information, knowledge and skill were needed for their performance. In exploitative situations, such production systems could operate with little regard to negative impacts on the physical, psychological, and social wellbeing of their human components.

Over the decades it became clear that production organised along Fordist lines, in the pursuit of profit maximisation and commoditisation, had led to several implications. Sites of production were moved from place to place in pursuit of tangible and intangible gains and stability. Such an industrial society, as Bell (1996, p. 147) stated, is 'a game against fabricated nature'. At its worst industrial society - technical, rationalised and centred on the production of commodities - treats humans as things because things are more easily managed within repetitive, modularised work designs than human beings.

The post-industrial (information or knowledge) society (Bell, 1996), on the other hand, is centred on services. People not only know one another, they have to 'love one another or die' (Bell, 1996, p. 149). Reality in the post-industrial society is not an externality - a given that has been designed by others and must be accepted - but something to be constructed and reconstructed, to be made and remade. Thanks to collaborative digital technologies knowledgeability, and therefore the potentiality for participation in continuous design, can be much more inclusive and broadly based. Perhaps as importantly, categories of knowledge not held by experts - 'grass roots' knowledge, in Giddens' terms tacit rather than discursive (Giddens, 1984, p .22) - can be brought strongly into play.

The challenge in design is to have an encompassing approach where both techno-centric and user-centric approaches are included; and where all contexts or realities are considered - in Bell's (1996) formulation the realities of the social world, the natural world, and the technical world.

Heightened consciousness and sensibility of all three inter-connected realities are necessary for sustainability of communities and society. 
This leads to the use of structuration theory as a foundation to discern the unintended consequences and non-explicit conditions of design. Bell (1996) proposes that this changing experience - from all things as objects to all things as 'a web of consciousness' (p.149) will create a change in consciousness and sensibility. The relationship between structuration theory and the approach of UCD argued in this paper will be further discussed in a later section.

\section{The co-evolution of techno-centric and user-centric ISD}

The emergence of UCD as a systems design approach has therefore been part of a movement in which ISD has developed a range of approaches across the spectrum of techno-centric to user-centric. Concepts and practices which were shaped by Taylorism and Fordism, together with user-centric approaches such as UCD, are all part of a wide range of options in ISD, the relevance of which depends on context.

As proposed by Taylor, 'scientific management' was based on the view that for most profitable results human activities could be measured, analysed, and controlled by techniques usually applied to physical objects (Doray, 1988). Ford went further, applying Taylorism in the automotive industry to achieve unprecedented levels of productivity and profitability. Even before Taylor the capacity of machines to divide complex work into 'bite-sized' tasks had been demonstrated in the textile factories of the British industrial revolution. The human consequences of regarding people as interchangeable components of technocentric production systems contributed to Marx's concept of 'alienation'.

In the developed world, human considerations in industrial production have over time increased through regulative action often spurred by trade union action (Gambino, 1996). On top of this, the transitions that have taken place, from pre-industrial, industrial, to the postindustrial society (Bell, 1996) reflect a requirement for a widened range of approaches to ISD - a range that includes adaptive UCD that moulds itself primarily to the human actor, and secondarily the technologies.

In the past 20 years the IS complex of disciplines has evolved significantly. It is not claimed that the adaptive, user-centric UCD approach, supported by structuration theory, argued for in this paper is radically new. The point has been well made that: 
The unequal power between managers of IS designers hired by them to Taylorise production and use of data systems has been criticised by researchers at least from the 1970s. Let me just mention Enid Mumford in the UK and Kristen Nygaard in Norway ... However all that has been and currently is undertaken to strengthen the position of ICT 'users'does not necessarily wave a flag with 'UCD' on it. (H. Nissen, personal communication, August 8, 2006).

The conceptual journey towards UCD gained pace in the 1980s. Penniman (1985) stressed the importance of user experience and satisfaction being included in the performance measurement of information systems. However after two decades Karat and Karat (2003) still characterise UCD as a relatively young discipline undergoing evolution. They observe that the term is still often used loosely, reflecting the changing scope and nature of UCD. There has yet to be a consistent agreement in the field with respect to the focus areas practised by the industry and academia, though all are agreed that UCD is fundamentally about understanding the needs of users, and harnessing such understandings in the design process.

Part of the change toward more user-centric orientations is marked by terms such as usability, user-centred design, human computer interaction, and user computing, being used almost interchangeably. Organisations express their own user-centric design philosophies differently. However all would claim a focus on the functional needs of users. Bernard (1998) acknowledges the diversity of interpretations of UCD, but notes that they are all agreed in distancing themselves from Taylorist principles.

Beyond these clear points of agreement there is a broad consensus in the UCD world that reality is 'mutable', there are 'no certain truths', and 'knowledge is constructed through communally created knowledge and action'. A principle advocated if not yet realised is that UCD involves the collective participation of many or all stakeholders, and it is this principle that the current research seeks further explore and relate to practical cases. 


\section{UCD - Practice or Aspiration?}

As already acknowledged, recognition of the merits of addressing the abilities of users in system design, is not new. Baroudi, Olson, and Ives (1986) found that user involvement in system design could lead to increased system usage and information satisfaction. Though the study does not point out the need to take into account user abilities beyond the provision of an information system (that is, in continuous and adaptive design) it does suggest the need to reconsider the measurement of user involvement and its related constructs.

Another conceptual frontier in UCD is whether the individual or the collective should be the primary focus of UCD. The Nielsen school of usability, for example, focuses extensively on the individual in front of the computer screen (Abelse, White, \& Hahn, 1998)

Merholz (c.f. Evans, 2002) refer to UCD as 'not a process, but a philosophy'. Simply put, it refers to the involvement of end-users throughout the design process. In contrast to the other methods of ISD, UCD is intended to be user-driven, concerned with the user's perspective of the system, involving end users in early stages of systems development (Alexander, 2003).

Smith (1997) made the point that although general ideas of UCD are well established in the academic and practicing communities, there is a lack of common meaning about the practice of UCD. Karat and Karat (2003) agree that there is a consensus in principle about the nature and intentions of UCD. However they find that there is no general agreement in terms of focus within the field of UCD - different organizations engage themselves in very different activities in their practice of UCD. Vredenburg, Isensee, and Righi (2002) provide the insight that when organisations claim a commitment to UCD all that can be generalised from this is that they try to focus on understanding what users need to know in a task situation as a way to inform design.

If, according to Merholz (c.f. Evans, 2002), UCD is a philosophy, then the literature on UCD has successfully conveyed one message: it is the core requirement of UCD to evolve all processes around users. That may sound simple enough - yet it is not an easily achievable feat given the increasing complexities of user communities. And more than ever, the process of computerisation has become inseparable from the social dynamics of the organisations and communities within which information systems are embedded (Agre, 1995). 


\section{Current approaches in UCD}

Practices and activities perceived as part of the UCD process of systems' development include participatory design (Abelse et al., 1998; Karat \& Karat, 2003), needs analysis (Allen, 1996), task analysis (Allen, 1996; Vredenburg, et al., 2002; Wei \& Salvendy, 2004), resource analysis (Allen, 1996; Vredenburg et al., 2002), user modelling (Allen, 1996; Vredenburg et al., 2002), and usability testing (Allen, 1996; Fraser, 2002; Twidale \& Nichols, 1998; Vredenburg et al, 2002). The essential contributions of some of these approaches can be summarised as follows.

- Needs analysis is concerned with understanding and analysing the information needs of users. Studies in this area have typically investigated the needs and uses of information situated within an information system. It is important to note that the background of this focus goes back to many cognate disciplines including psychology, sociology, political, and organisational theory (Allen, 1996). This reflects the complex and diverse nature of assessing information needs, which are deeply seated in the interplays of individual, social, organisational, and group influences with information behaviour.

- Task analysis is concerned with making explicit the specific, essential tasks of users as they interact with information systems. It analyses in detail how these tasks are being performed by users, through consideration of subtasks (Allen, 1996). There is a similarity between task analysis and the functional needs of users as discussed by Smith (1997). Smith identifies Caroll's taskartefact cycle as a key development in task analysis. The taskartefact cycle has mostly been used in the study of humancomputer interaction, notably for establishing the settings for usability studies (Allen, 1996; Smith, 1997). The task artefact cycle aims to help define the requirements of artefacts in a system and is based on the concept of iterative product lifecycle. Once initial tasks are defined for an artefact, it is put into operational use. Through such use, new possibilities for the same artefact will be generated. The cycle then starts again, providing requirements which gives rise to new or refined artefacts.

- Individual versus groups as units of analysis. There is a debate in UCD about the relative importance of focussing on individuals 
or groups. So far the study of tasks has mostly evolved around individuals. However, there is a growing concern for tasks that are not only individualistic, but social or collective as well. Kukla, Clemens, Morse, and Cash (1992) argue that understanding the dynamics of the organization in which users are situated must complement the analysis of tasks addressed and for which an information system is designed. This is especially important in settings where tasks are performed collaboratively by users in groups, whether formal or informal. The mapping of individual against group tasks and the impact of collective task performance on individual performance have only recently begun to feature in UCD studies (Berger \& Hines, 1992).

These current approaches in UCD practices form the baseline of our work which endeavours to rethink UCD in terms of community culture. As mentioned earlier, community in this study refers to any collectivity in which meaning ('knowledge') is made, including communities of practice, local communities, ethnic or religious communities. Community culture comprises the ongoing interplay of action and social structure through which meaning is constructed in the minds of individual participants.

\section{Designing for Control and Flexibility in Knowledge Production}

To government and business organisations, traditionally characterised by a relatively high degree of control, passing through the PC/I threshold has offered almost limitless potential for personnel to act with flexibility, both individually and collaboratively. However these opportunities have been embraced only partially and with caution because of the perceived risks of decreased control.

For civil society collectives such as associations and social movements the barriers to strongly effective ICT take-up have been more complex - largely due to the vast diversity in scope and scale of civil society collectives, and the relatively limited resources both in money and skills that can be brought to bear.

Visions of the full potentialities of ICT beyond the PC/I threshold have given rise to notions such as the learning organisation, the knowledge economy and the knowledge society. They have found expression in emergent professional disciplines in the IS cluster such as Knowl- 
edge Management and Community Informatics. Within IS, understandings of the post PC/I threshold state have given rise to approaches such as soft systems methodology, and brought prominence to Applied Structuration Theory and Actor-Network theory.

Each of these approaches provides insights regarding the contention between control and flexibility, whether through lenses of technocentric versus user-centric design, or of standardised versus customised ICT regimes for information management and ICT governance.

\section{Purpose, Emergence and Knowledge-based Models of Production}

Information systems and technologies have often been viewed as external forces with predictable impacts. Much research has evolved around this assumption - attempting to anticipate and assess these impacts. Recently attention has shifted to the 'social reality' of technologies - recognising that the use and development of technologies can occur in organisations for a range of very different reasons arising from the changing properties of a complex social setting. It is because of this recognition that the phenomenon of emergence and the social construction of technologies have become critical issues in UCD (Liker, Hadad, \& Karlin, 1999).

The concepts and practices of information systems design are being inexorably influenced by this changing frame of reference. The traditional 'waterfall' approach to systems design focuses on the use of technologies to manage functional tasks to be undertaken by targeted groups of users. Known goals, purposes, and processes are at the centre of the frame (Pinch \& Bijker, 1989).

Even a relatively recent definition of information systems lays strong emphasis on the attainment of known goals. Preece, Sharp, \& Rogers (2002) suggests that information systems are systems designed with an intended purpose for a targeted community of people (recognised as 'users' by designers and developers), with underlying policies governing its use, with required hardware and software supporting the requirements of these information systems. In contrast an earlier definition is more fluid in its conceptualisation of the same phenomenon. Allen (1996) defines an information system as a linked and related system of entities (including one or more information devices) that provides ac- 
cess to one or more bodies of knowledge and acts as a mechanism through which individuals can inform or become informed.

Despite the divergence exemplified in these two formulations, the position of 'traditional' ISD could be expressed as follows. Information systems are purposeful, and set out to achieve one or more sets of goals. These purposes and goals are determined by targeted groups of people. With underlying policies governing their use, they usually consist of a systematic integration of hardware and software. Information, as well as the communication of it, is a key element of information systems.

This kind of conceptualisation has been the subject of a mounting critique from within the IS discipline. The traditional systems development life cycle is a structured approach to systems development that separates the functions and duties of IT specialists and knowledge workers (Haag, Cummings, \& Dawkins, 1998, p. 345). The six steps typical of this approach are: planning, scoping, analysis, design, implementation, and support. The approach was widely used by organisations in the 1970s and early 1980s but has met a range of criticisms mainly because of its perceived incapacity to consider the needs of users comprehensively.

Some critics (Pinch \& Bijker, 1989) characterise this shortcoming in terms of its excessive focus on artefacts. It is assumed that an information system's 'product' developed in one context will necessarily translate to another without much effort devoted to fundamental assessment and explanation. This is reminiscent of the saying that if your only tool is a hammer, all problems will be treated as nails.

Returning to our earlier proposition that personal computing and the Internet marked the emergence of a fundamentally new techno-social condition, it can be argued that a concern with 'usability' as conceived by Nielsen and his followers, while very helpful in day-to-day interface evaluation, is only one aspect of UCD.

The distinction between techno-centric and user-centric ISD is this. Techno-centric ISD assumes the classic conditions of the 'waterfall' and 'lifecycle' approach, where systems design is seen as a major creative intervention followed by a lengthy period of routine operation within the framework established. The user-centred approach, on the other hand, assumes continuous and simultaneous processes of observation, analysis, action and adjustment. Often these processes unfold in 
conditions where entire cycles cannot be completed before the next adjustment is required. Most importantly every adjustment affects the whole - in structurational terms the emergent 'culture' both shapes and takes shape.

Breaking through the PC/I threshold has embedded information systems so deeply in our everyday lives that our dealings with information systems in a design sense have become partly deliberate, partly intuitive, like the footballer responding to and initiating change in the flow of the game.

Information systems are forgotten as often as they are remembered in the conduct of everyday life, and have long since overflowed their original ambit of the workplace to include almost all other aspects of living. So extensive are the potentials of information systems in the post PC/I threshold world that the term 'information systems' has become too diverse a concept to be captured in any short definition. Information systems - when considered as an object of study - require constantly renewed effort at definition depending on context. It is now a reality of the techno-social condition that people need to grapple continuously with the multiple personae of 'information' and 'information systems' while interacting with them to fulfil their everyday activities.

Away from a supply-oriented view of UCD, which envisions users as groups of people waiting for deliveries, this paper proposes an approach which includes a reflexive process of participative, community and action based interpretations.

\section{Systems Informed by Structuration Theory}

With this in mind, a vision of technologies informed by structuration theory is discussed; one that is integrated in its form and can be applied to both the technological and human dimensions of collaborative endeavours. In the study of ICT, there are broadly two traditions of assumptions: social reality as subjective or objective (Orlikowoski \& Robey, 1991). Research assuming the subjectivity of social systems focuses on individual, internalised human experiences, interpretation of them, and their expressions through human behaviour modifying the world. The contrasting view of objectivism focuses on the externalised properties of institutions shaping social systems, providing explanations for their influences on human actions and relationships. Structuration theory as developed by Giddens views the subjectivity and objectivity 
of social realities as equally important. According to structuration theory, cultural context is generated and regenerated through the interplay of action and structure. It recognises that 'man actively shapes the world he lives in at the same time as it shapes him' (Giddens, 1982, p. 21).

The user-centred methodology of design draws on similar principles. The design of information systems, however exhaustive, imposes certain forms of structure on its users. Yet this process of design must also call on the human actions shaping the eventual structure of information systems. More information systems researchers are now arguing the case for iterative design (Carroll, 2000; Preece et al., 2002) as a way to factor in the effects of human actions - but more critical for cultural institutions is the importance of factoring in the cumulative actions of communities as a whole, and incorporating this in the design methodologies of information systems, services, and workspaces. It is not only about the delivery of services by cultural institutions, but includes dialogue and innovation for communities - a key objective of the knowledge commons.

As Rose and Scheepers (2001) pointed out, while the use of structuration theory to theorise the field of information systems and its empirical scenarios is not new, there has been little effort made in using the theory to influence practice. Structuration theory is complex and must be carefully adapted to specific contexts in order to operationalise it to an applied methodology. Orlikowski and Robey have done much in theorising information systems using structuration theory. According to them, 'in its constituted nature - information technology is the social product of subjective human action within specific structural and cultural contexts - and [in] its constitutive role - information technology is simultaneously an objective set of rules and resources involved in mediating (facilitating and constraining) human action and hence contributing to the creation, recreation and transformation of these contexts' (Orlikowski \& Robey, 1991, p. 151).

As already suggested, so extensive are their potentials that information systems have become too conceptually diverse to be captured in any short definition. Information systems, when considered as an object of study, require a constant renewal of definition depending on context. It is a reality that people need to grapple continuously with the multiple personae of 'information' and 'information systems', as expounded in Buckland's (1991) discussion of 'information as thing'. Clearly this 


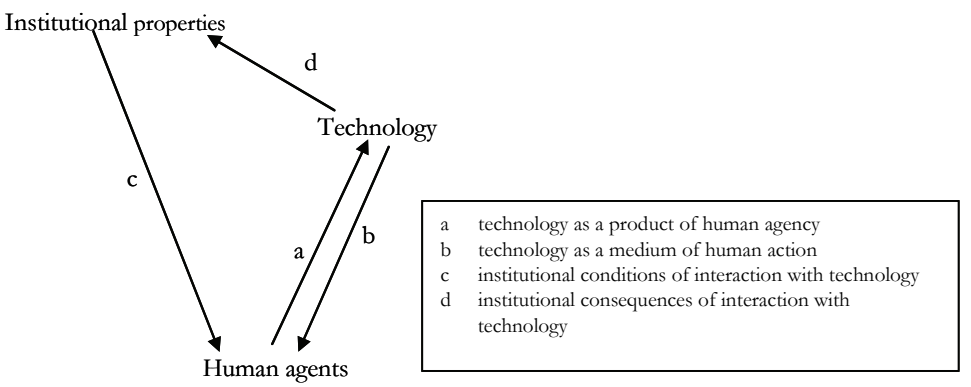

Figure 1. Structurational model of technology

(Orlikowski, 1992, p. 410)

highly dynamic interaction with information systems needs to be accounted for. Orlikowoski (1992, p. 410) depicts a recursive model of information technologies using structurational theory (Figure 1).

The recursive nature of technologies based on structuration theory is manifested in the properties of technologies as being created and changed by human action; but also both supporting and constraining such actions.

In the case of cultural institutions the trajectory becoming discernable (albeit still faintly, like the changing quality of light preceding the dawn) is a trend towards design as a much more inclusive phenomenon. This trend moves from a 'subject-object' (expert to user) vision of service delivery, towards a culture of continuing collaborative design in which expert-to-peer, and peer-to-peer, dialogue and learning continuously shape and re-shape systems, services, and spaces. This is design conceived of as collaborative innovation by communities. The proposition being explored in this research is that such design is a key attribute of the knowledge commons. It is readily observable in the open source software movement. Its emergence within the realm of cultural institutions is less obvious to discern, but observable particularly where 'new media' and community memory are being brought into creative conjunction. Referring to collective memories of communities that are shared and understood both implicitly and explicitly (Pang, Denison, Johanson, Schauder, \& Williamson, 2006), researchers have noted incipient paradigm shifts in the ways cultural institutions are positioning themselves in communities. Dale, for example, argued the case for mu- 
seums as agents of change in communities. As mainstream cultural institutions, museums have a significant role in 'creating public understanding and knowledge of the world' (Dale, 2003). In her paper, Dale gave examples of how museums around the world are repositioning themselves as agents of cultural change, by collecting, preserving and facilitating alternative discourses and knowledge.

\section{Structuration Theory and Its Application to User-Centred Design}

The dynamic interplay of user needs and feedback (action) and translating these needs into some practical specification of requirements for any information system (structure) cannot be satisfied in a linear, nonrecursive methodology of design. As Bonner (2002) pointed out, users have found it difficult to communicate ideas or concepts beyond their own experiences. Many practitioners have also found problems with the classic process of attempting to capture user needs; that they are poorly timed, time-consuming and costly. The iterative view of usercentred design implies that there can never be a finalised information system for the community to use (Cockton, 2004; Fraser, 2002; Head, 1999). Perhaps it is not a difficulty to be resolved - but a condition or state of open-ended opportunity to be continuously negotiated between cultural institutions and communities.

It is this interpretation of the relationship between people and information systems that leads to characterising UCD as a process of emergence rather than known purpose, and to propose as its appropriate 'design' methodology a reflexive process of participative, community and action based, interpretations. This approach to UCD draws its procedures, and its explanatory and prescriptive power, from the interpretive study of communities in which people live and work - a basic tenet of structuration theory. It requires the study of people at multiple levels from the individual and small group to large collectivities, distinct from the typical study of people in an artificially reductionist way as users of a system under design or evaluation. In other words, the study of people and their interactions with information technologies is aimed to be holistic - taking accounts of the multiple cultures of communities in which people are embedded. 


\section{A Case-based Program of Research}

The development of a community-based approach to UCD is much assisted by having a framework for considering the communicative interactions of human collectives. Linger (2002) in consultation with colleagues from the information management and systems disciplines at Monash University arrived at a model extending the task-based approach to Knowledge Management across individual to societal levels of analysis and engagement. This formulation is influenced by the Information Continuum Model (ICM) developed as a research and teaching framework for Information Management at Monash University. The ICM is built on key structurational insights from Giddens and other action-structure theorists as applied to the creation, capture, organisation and pluralisation of information at the levels of individuals, groups, organisations, and societies (Schauder et al., 2005). The Linger model is found in Figure 2.

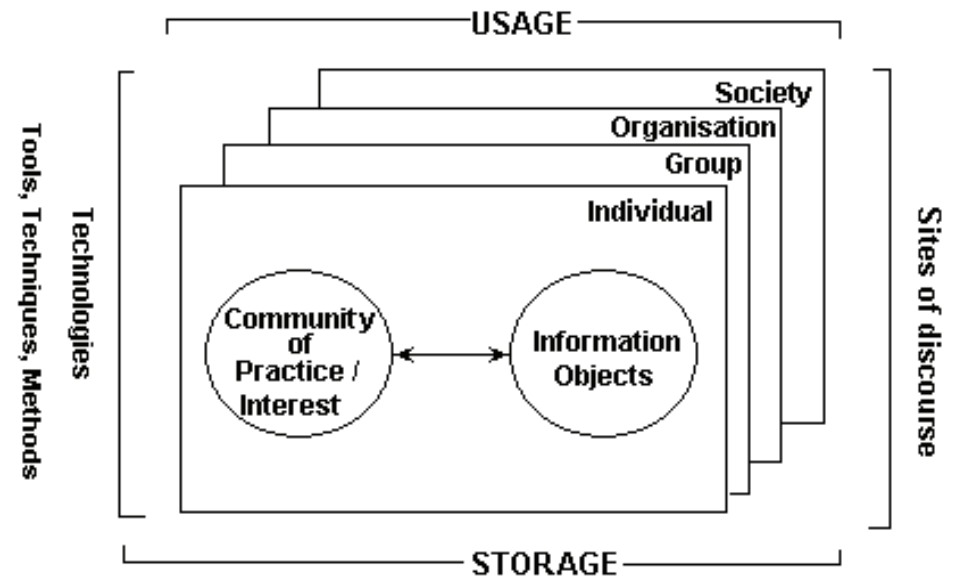

Figure 2. The Linger model (2002) (adapted)

It is a priority of the study to elucidate UCD issues at both individual and group levels. The concept of community is bound up with various kinds of group affiliation or belonging by individuals; understanding that individuals belong to multiple communities. The project is interested in exploring the achievement of systems-design 'fit' for both indi- 
viduals and groups, and the ways in which group participation influences the design expectations, participations, and evaluations of individuals where activities (perhaps a wider category than tasks) are being undertaken collaboratively. Many user studies have focused on the user as a single unit of analysis; assessing their behaviours and needs while studying them as an individual. Our focus for a renewed vision of $\mathrm{UCD}$ is on the interaction between the individual and the group, and the community culture generated by the interplay against the backdrop of wider social structuring processes - a structurational approach. In this study, the model is conceptualised as below:

\section{- Communities and information objects}

In the context of communities and cultural institutions, information objects are defined as the public resources cultural institutions seek to provide for communities. Depending on the cultural institution, this may include literary works, digital resources, spaces, moving pictures and other multimedia, community information, and so on. These information objects come about through the construction and reconstruction of cultures by communities. They have both structural and agency relationships with communities, and vice versa.

\section{- Layers/levels of interactions}

The interactions between communities and information objects are contextualised using four layers of interpretations. It is recognised that these four layers are merely points along a typological continuum. At the individual level, the individuals make sense of their own self-knowledge and engage in private projects. This is a vital component in the construction of knowledge which may later be re-contextualised and/or reshaped by other layers of interpretations.

The individual thus contributes to the production of knowledge by the community (as seen as the 'group' layer in Linger's model). This is in turn shaped by organisational influences, referring to cultural institutions in this project. It should also be highlighted that organisations, while they have an influence on the communities and their interactions with information objects, are also significantly influenced by the very dynamics of these interactions at the community level. The fourth and 
overarching layer lies at the societal level of interpretation - shaping the actions of cultural organisations and their constituent communities while at the same time being shaped by them (among many other agencies).

These layers of interpretation relate also to two poles of a spectrum of information systems. At one pole is the storage of information objects. The other relates to the usage of information objects, for example in the context of the knowledge commons. The usage end of the spectrum is where this study mostly concentrates.

A challenging insight on 'conservative' UCD is provided by Spinuzzi's characterisation of the user as a 'victim' to 'rescued' (Spinuzzi, 2003). Such an interpretation can be drawn from UCD literature that concentrates on the adeptness of designers, developers, usability specialists and managers to capture the needs of users effectively, but go no further than providing effective interfaces and systems to 'rescue' end users. In the notion of harnessing community dynamics in design, where members in the community create, access, contribute to, and own resources collaboratively, the perspectives of users are such that they are not merely users, but co-producers and participants in the things that are meaningful to the communities in which they are participants.

At the core of this concept of UCD is a design matrix of technologiesuser adaptation. This is intended to be used as a basis for monitoring various states of technological acceptance by individuals and communities studied in various case studies. The paper draws on the statistical concept of standard deviation to visualise options for technologies in use within a community. In statistics, standard deviation is a measure of the range of variation from an average of a group of measurements. In a normal distribution $68 \%$ of all measurements fall within one standard deviation (1S, $-1 \mathrm{~S}$ ) of the average $\bar{x}$, and $95 \%$ of all measurements fall within two standard deviations $(2 \mathrm{~S},-2 \mathrm{~S})$ of the average. In this case the variable being considered is the degree of satisfaction with the technologies-in-use among community members. If the normal distribution is visualized as a bell-curve, a 'steep' bell curve will mean high consensus, while a 'flat' bell curve will mean low consensus. Depending on the specific situation it might be possible to calculate standard deviation in the classic statistical way, but more likely a qualitative conclusion analogous in nature would be achieved using ethnographic techniques. Irrespective of the way that an estimate of variation is argued, the point is that degree of acceptance of technologies in use by individual com- 
munity members would be compared or contrasted with the degree of acceptance by all community members.

By visualising the community using the concept of standard deviation we can plot the situation of different communities on a Cartesian coordinate diagram as shown in Figure 3.

The horizontal and vertical axes indicate degrees of acceptance of the existing information technologies by individuals, and by the communities to which they belong. For illustrative purposes, the paper discusses four representative cases - which eventually lead to monitoring the backgrounds of the selection of cases in this study. These examples are are denoted by A, B, C, and D in the figure.

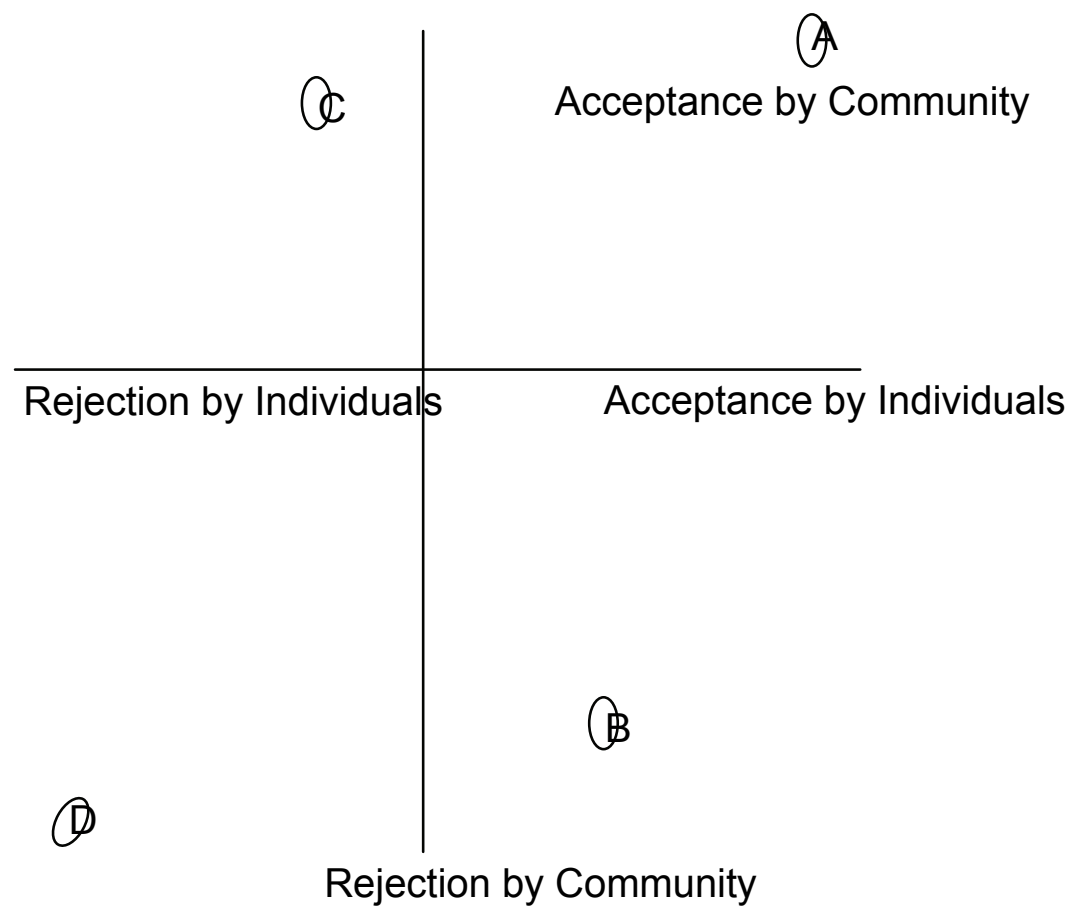

Figure 3: Cartesian co-ordinate diagram of technology in use by individual community members versus the degree of acceptance by all community members 
A. The technologies-in-use are accepted by the whole community as congruent with their needs. From the viewpoint of UCD, the system-state should be monitored for ongoing user acceptance and technical performance. This is a desirable system state to be in - where acceptance is high for both individual users and communities. New systems to be implemented are initiated with a good understanding of what is desired by the community.

B. The technologies are acceptable to some individuals but not to the community as a whole. This is a UCD problem susceptible to adaptation. The technologies should be adapted to satisfy the wider community while not losing utility for those who already find them acceptable, for example by the addition of assistive technologies for a user with disabilities.

C. Acceptance of technologies-in-use by some individuals is low, yet acceptable to the community as a whole. This is a UCD problem susceptible to adaptation. Members of the community can engage in adapting themselves to the technologies in use to reach an acceptable degree of congruence between the technologies and the community's shared meanings, for example through training or peer support.

D. The technologies are rejected by the community as a whole as incongruent with their needs: acceptance of technologies-inuse by both individuals and the community as a whole is low. This is a critical UCD problem. The system-state should be analysed both in regard to user needs and technological affordances for radical re-design.

This project seeks to advance understanding and definition of UCD both in theory and practice through focusing on how people as individuals and in communities act, and in doing so interact with (adjust to or change) the structures, especially the information systems, that both enable and constrain their scope of action.

\section{The Case of a Digital Collection}

In the first half of 2005 discussions were held with individuals and groups across the university to identify cases through which the concepts and phenomena discussed above could be observed and explored in the context of cultural institutions. Contact with researchers in Pub- 
lic History resulted in engagement with collaborative project involving historians, museologists and a grass roots movement called The Women on Farms Gathering (WoFG). WoFG is a forum in which women from a rural background, whether themselves farmers or connected in other ways with farming, could build better understandings of their own lives and experiences, and convey these understandings to the wider (mostly urbanised) Australian population. Part of this endeavour envisaged a physical and virtual exhibition, focussing on artefacts and other objects to which meanings were or could be attached. The first step was to negotiate with WoFG members whether such a case study might be feasible, and how the researchers could position themselves to gain in-depth insights concerning the WoFG community. There was initially some concern about engagement with researchers from an IT background. Where community members had previous experience of IT researchers this was not necessarily regarded as an advantage. One participant wrote:

I don't mean to caste aspersions on IT researchers as such, but frequently there's a lack of sensitivity about the different needs in rural communities, and ways to get research 'out there' in a credible fashion. (Lottkowitz, 2005, p. 1)

She also commented:

... I have a sense from the early discussions about this project that it needs to be women focussed and driven, and IT is not always friendly for many women in the communities of interest. (Lottkowitz, 2005, p. 2)

Yet it is notable that this same participant distributes an e-bulletin to rural communities, in a simple format able to be readily accessed with minimal equipment. She recognised the irony of her commitment to that system alongside her scepticism about the involvement of IT researchers.

This 'us and them' tension is a manifestation of the kind of problem in information systems design practice that our proposed communitybased, adaptive approach to UCD seeks to address. Discussion with a history academic involved in the WoFG project conjured the analogy of the Procrustean bed. This refers to the ancient Greek account of a person named Procrustes who offered hospitality to travellers, claiming that his bed exactly fitted the length of each guest. He did not reveal 
that this was achieved by stretching the guests or chopping off their legs to obtain the correct fit. Those inside the IT professions may under estimate the extent to which users suspect the Procrustean approach to be the underlying methodology of ISD.

Such comments and experience seem to support concerns expressed in the kind of literature referred to in earlier sections that something is out of kilter in the conceptualisation and practice of information systems, even where those involved believe they are doing their utmost to consider user needs.

The WoFG public history project became, through mutual agreement, the principal case study for the project. It is briefly described here to illustrate how the community-based approach to design, which the sections above have sought to justify theoretically, was deployed in the 'real world' context of the WoFG project. The case summary in Figure 4 provides a summary of the background and analysis that took place. Much of this analysis has been based on the preliminary model development for the proposed community-based centred design approach (see Figure 2).

\section{The Community:}

Emerged from a grassroots endeavour, beginning with with a gathering of farm women in the state of Victoria, Australia in 1990, for sharing of insights and experience on issues of common importance. A collection of significant objects was established in 2001 with the involvement of Museum Victoria. The partnership between the Museum and the community is different from the general model for the development of museum exhibits which primarily express the understanding and vision of the curator. With the WoFG exhibit the curator involved, supported by the public history scholars at Monash Universty, attempted from the outset to keep the community in equal engagement. This approach conceives of the Museum as a central and neutral entity for the purpose of ensuring the sustainability of the collection, and not the sole or even primary interpreter of the meaning of the collection.

\section{Information objects:}

Take the forms of stories, symbolic icons, gathering reports, responses to stories, oral histories, and other memories from members of the community. On their own few of these objects have intrinsic value but their meanings are constructed by the community collectively through 
what Giddens calls the 'interpretive' modality - resulting from the interplay of communication (action) and signification (structure) (Giddens, 1984, p. 28-29).

\section{Technologies-in-use:}

Email was the most prevalent technologies used in the community for communication purposes. At the beginning of the project, while some individuals found this quite acceptable to overcome difficulties posed by physical distances, the community as a whole decided in a periodic meeting that they needed to communicate the shared information objects publicly and more dynamically within and beyond the community. The desire for upgraded information systems was also driven by a need to gather memories and stories for the collection in a more effective way. There was a strong, shared motivation to take this next step in information management, because of the rapid changes affecting rural society and the sense that significant understandings could be lost.

\section{Tasks and needs in contexts:}

Once these requirements were realised the tasks and needs of the community were analysed and written down in context. Alongside the members of the community, the museum curator, and the public historians, the IT reseacher were given access to the dynamics of the project as developers of virtual exhibition website, and to help build relevant IT skills among WoFG members. It was understood from the outset that, if the exhibition succeeded, the pilot system and ongoing design would need to interoperate with the Museum's mainstream information systems.

\section{Figure 4: Case summary}

Engagement with the WoFG case led to the development of a digital collection using the UCD proposed approach argued for in this paper. It may very well be that the same requirements and system outcomes could have been generated by other approaches - but the process that both the community and Museum went through via the adaptive community-oriented UCD approach was seen by the WoFG participants as empowering, rather than disempowering. This was demonstrated by members who were initially apprehensive about the project taking ownership of content management and learning the administrative functionalities of the system. Having the system deeply grounded in the cultural context the WoFG community ensured a sense of continuing 
engagement and control, rather than a 'hand-over' or alienation of significant objects and the accompanying heritage to 'the experts'. The system is now integrated into a mobile exhibition for the community's annual gatherings, and has become a part of the communicative interactions that help in the constructing and re-constructing of identity by the community.

Further case studies concerning cultural institutions in their relation to communities, technologies and the knowledge commons will be added to that of the WoFG/Museum Victoria case to complete the project, and a fuller account of the WoFG and other cases will be given in future publications.

\section{Conclusion}

The main features of the adaptive UCD approach being explored through the theoretical argument and case study introduced in this paper are that UCD is seen as an integral part of the culture of communities. Community culture is produced and re-produced through structuration - the continuous interplay of human action and social structure. Technologies such as ICT are a crucial element of structure. Adaptive UCD thus becomes more an emergent than a deterministic process, as predicated by complexity theory. The rationale behind the approach is well summarised by Price (2004):

As a metaphor of holism it [complexity] has become a powerful counter to mechanistic views of organizations and organizational change. Proponents of a retreat from Newtonian theories of organisation or Taylorist approaches to management find common ground in this form of 'complexity'.

In this view, UCD becomes an increasingly essential part of community culture when members of the community, as an accustomed part of their work or life style, continually 'read' the system-state through interpreting needs and meanings in the community, and act to alter it for maximum acceptability. UCD understood in this way both fosters and is made possible by reflexive processes of participative, community and action based, interpretation - which both shapes and is shaped by community culture. 


\section{Acknowledgements}

We would like to thank the reviewers for their comments and Professor Hans-Erik Nissen for his time and extensive study of our paper. Without them this paper would not have been possible.

\section{References}

Abelse, E. G., White, M. D., \& Hahn, K. (1998). A user-based design process for web sites. Internet Research, 8(1), 39-50.

Agre, P. E. (1995). Conceptions of the user in computer systems design. In P. J. Thomas (Ed.), The Social and interactional dimensions of human-computer interfaces (pp. 67-106). New York: Cambridge University Press.

Alexander, D. (2003). Redesign of the Monash University web site: A case study in user-centred design methods. In AusWeb 2003 Conference, Sanctuary Cove, 5-9 July. Retrieved November 2, 2005 from http://ausweb.scu.edu.au/aw03/papers/alexander

Allen, B. L. (1996). Information tasks: toward a user-centered approach to information systems. San Diego: Academic Press.

Baroudi, J. J., Olson, M. H. \& Ives, B. (1986). An empirical study of the impact of user involvement on system usage and information satisfaction. Communications of the ACM, 29(3), 232-238.

Bell, D. (1996). The cultural contradictions of capitalism. New York: Harper Collins.

Berger, K.W. and Hines R.W. (1992). What does the user really want? The library user survey project at Duke University. The Journal of Academic Librarianship, 20(5/6), 306-309.

Bonner, J. V. H., \& Porter, J. M. (2002). Envisioning future needs: From pragmatics to pleasure. In W. S. Green \& P. W. Jordan (Eds.), Pleasure with products: Beyond usability (pp. 151-161). New York: Taylor \& Francis.

Buckland, M. (1996). Information as thing. Journal of the American Society for Information Science, 42(5), 351-360.

Burstein, F., \& Linger, H. (2003). Supporting post-Fordist work practices: A knowledge management framework for supporting knowledge work. Information technology and people, 16(3), 289-305.

Carroll, J.M. (2000). Making use: Scenario-based design of human-computer interactions. Cambridge: MIT Press.

Cockton, G. (2004). From quality in use to value in the world. In Proceedings of the 2004 Conference on Human Factors in Computing Systems (CHI'04), Vienna, Austria (pp. 1287-1290). New York: ACM Press. 
Culnan, M. J. (1984). The dimensions of accessibility to online information: Implications for implementing office information systems. ACM Transactions on Office Information Systems, 2(2), 141-150.

Dale, L. (2003). Stories and storytelling: A cultural partnership between Museum Victoria and the Victorian Women on Farms Gathering. In R. O'Hagan, M. Alston, \& S. Spriggs (Eds), Setting the agenda for rural women: research directions (pp. 70-87). Wagga Wagga: Centre for Rural Social Research.

Doray, B. (1988). From Taylorism to Fordism: A rational madness. London: Free Association Books.

Evans, M. (2002). User-centered design. Retrieved April 8, 2005, from http://www.digitalweb.com/articles/peter merholz and nathan shedroff/

Faulkner, C. (1998). The essence of human-computer interaction. New York: Prentice Hall.

Fraser, J. (2002). The culture of usability. New Architect, 7(8), 26-29.

Gambino, F. (1996). A critique of the Fordism of the Regulation School (E. Emory, Trans.). Common Sense, 19, 42-63.

Giddens, A. (1982). Profiles and critiques in social theory. Berkeley: University of California Press.

Giddens, A. (1984). The constitution of society: Outline of the theory of structuration. Berkeley: University of California Press.

Gurstein, M. (Ed.). (2000). Community informatics: Enabling communities with information and communications technologies. Hershey, PA: Idea Group.

Haag, S., Cummings, M. \& Dawkins, J. (1998). Management information systems for the information age. Boston, MA: Irwin McGraw-Hill.

Head, A.J. (1999). Web redemption and the promise of usability. Online, 23(6), 20-32.

Karat, J. \& Karat C. M. (2003). The evolution of user-centered focus in the human-computer interaction field. IBM Systems Journal, 42(4), 532-541.

Katsikides, S. (1998). The societal impact of technology. Aldershot, Hants: Ashgate.

Kaufer, D. \& Carley, K. (1993). Communication at a distance: The influence of print on sociocultural organisation and change. Hillsdale, New Jersey: Lawrence Erlbaum Associates.

Kukla, C. D., Clemens, E. A., Morse, R. S., \& Cash, D. (1992). Designing effective systems: A tool approach. In P. Adler \& T. Winograd (Eds.), Us- 
ability: Turning technologies into tools (pp. 41-65). Oxford: Oxford University Press.

Liker, J. K., Haddad, C. J. \& Karlin, J. (1999). Perspectives on technology and work organization. Annual Review of Sociology, 25, 575-596.

Linger. (2002). Conceptualising IMS [diagram]. Unpublished - used with permission.

Lottkowitz, A. (2005). Email to Marian Quartly, 23 May 2005. Unpublished used with permission.

Mackenzie, C. (2002). The need for a design lexicon: Examining minimalist, performance-centered, and user-centered design. Technical Communication, 49(Nov), 405-410.

Mann, J. (2002). IT education's failure to deliver successful information systems: Now is the time to address the IT-user gap. Journal of Information Technology Education, 1(4), 253-268.

Norman, D.A. (1986). Cognitive engineering. In D.A. Norman \& S.W. Draper (Eds.), User centred systems design: New perspectives on buman-computer interaction (pp. 31-61). New Jersey: Lawrence Erlbaum Associates.

Orlikowski, W. J. (1992). The duality of technology: Rethinking the concept of technology in organizations. Organization Science, 3(3), 398-472.

Orlikowski, W. J., \& Robey, D. (1991). Information technology and the structuring of organizations. Information Systems Research, 2(2), 143-169.

Pang, N., Denison, T., Johanson, G., Schauder, D., \& Williamson, K. (2006). Empowering communities through memories: The role of public libraries. In $3^{\text {rd }}$ Prato International Community Informatics Conference Proceedings (Italy), Prato, Italy (pp. 1-22). Italy: Monash Centre Prato.

Penniman, D. W. (1985). Information system performance measurement revisited. In Proceedings of the 1985 ACM Computer Science Conference (USA), New Orleans, USA (pp. 29-32). USA: ACM Press.

Pinch, T. J. \& Bijker, W. E. (1989). The social construction of facts and artifacts: Or how the sociology of science and the sociology of technology might benefit each other in the social construction of technological systems. In W. Bijker, P. Hughes, \& T. Pinch (Eds.), The social construction of technological systems: New directions in the sociology \& history of technology (pp. 1750), London: The MIT Press.

Preece, J., Sharp, H., \& Rogers, Y. (2002). Interaction design: Beyond bumancomputer interaction. New York: J. Wiley \& Sons. 
Price, I. (2004). Complexity, complicatedness and complexity: A new science behind organizational intervention? E:CO 6(1-2), 40-48.

Rose, J., \& Scheepers, R. (2001). Structuration theory and information systems development: Frameworks for practice. In Proceedings of the $9^{\text {th }}$ European Conference on Information Systems Development, Bled, Slovenia (pp. 217-231). Slovenia: University of Maribor.

Schauder, D. (2002). Post-script: Seven questions for information management and systems researchers. In K. Williamson (Ed.), Research methods for students, academics and professionals (pp. 321-329). Wagga Wagga NSW: Charles Sturt University, Centre for Information Studies.

Schauder, D., Johanson, G. \& Stillman, L. (2005). Sustaining a community network: The information continuum, e-democracy and the case of VICNET. Journal of Community Informatics, 1(2), 79-102.

Schauder, D., Johanson, G., \& Taylor, W. (2006). Libraries, ICT policy and Australian civil society: Issues and prospects from national consultations. In the proceedings of $V A L A 2006$, at: http://www.vala.org.au/vala2006/auth2006.htm

Smith, A. (1997). Human computer factors: A study of users and information systems. New York: McGraw-Hill.

Spinuzzi, C. (2003). Tracing genres through organizations: $A$ sociocultural approach to information design. Cambridge: MIT Press.

Stowell, F. (1991). Towards client-led development of information systems. Journal of Information Systems, 1(3), 173-189.

Twidale, M., \& Nichols, D. (1998). Designing interfaces to support collaboration in information retrieval. Interacting with Computers, 10, 177-193.

UNESCO. (2003). Virtual exhibition: Building knowledge societies. Retrieved November 1, 2006, from http://portal.unesco.org/ci/en/ev.php-

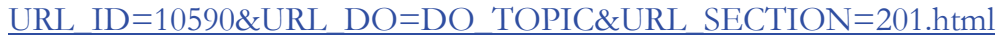

Vredenburg, K., Isensee, S. \& Righi, C. (2002). User centered design: An integrated approach. London: Prentice Hall.

Walsham, G. (2001). Knowledge management: The benefits and limitations of computer systems. European Management Journal, 19(6), 599-608.

Wei, J., \& Salvendy, G. (2004). The cognitive task analysis methods for job and task design: Review and reappraisal. Behaviour \& Information Technology, 23(4), 273-299.

Wellman, B., \& Haythornthwaite, C. (2000). The Internet in everyday life. Oxford: Blackwell. 
Whyte, W. (1986). On the uses of social science research. American Sociological Review, 51(4), 555-563.

Wenger, E., \& Snyder, W. (2000). Communities of practice: The organizational frontier. Harvard Business Review, 78(1), 139-145.

\section{Biographies}

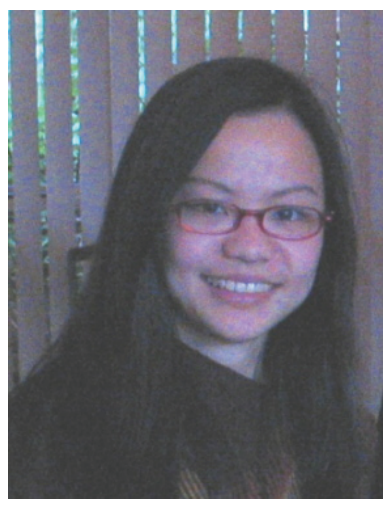

Natalie Pang is a PhD candidate in

Monash University's Faculty of Information Technology. Her research investigates the interplay between design and the knowledge commons in communities and cultural institutions. Her other research and teaching interests include information management, usability evaluations, peer to peer technologies and approaches, and digital libraries. A graduate of Melbourne University in Australia and Nanyang Technological University in Singapore, Natalie has worked in

Singapore, Malaysia, and Australia. She has also served as an Honorary Research Associate of Museum Victoria in Australia, and is currently a Visiting Scholar at the School of Communication and Information, Nanyang Technological University in Singapore.

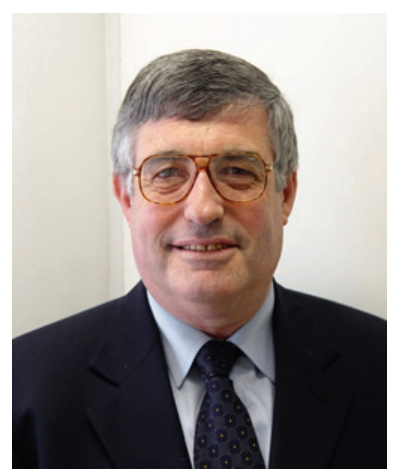

Don Schauder is Professor of Information Management in the Faculty of Information Technology, Monash University. He is Chair of the Information \& Telecommunication Needs Research Group (ITNR), and of the Centre for Community Networking Research (CCNR). The foci of his teaching and research are developing information products and services that benefit individuals, organisations and society; and facilitating the transfer of knowledge among people. He was a pioneer of electronic publishing in Australia, and a cofounder of the international Community Informatics Research Network (CIRN). 